Vol. LXVII 2015

\title{
INDUSTRIAL APPLICATION OF PSYLLIUM: AN OVERVIEW
}

\author{
KHALIQ Rehana, Ph.D Student \\ Faculty of Agricultural Sciences, Food Industry and Environmental Protection, Lucian Blaga University of \\ Sibiu, Romania.e-mail: rehanakhaliq1@gmail.com \\ TITA Ovidiu, Prof.univ.dr.ing \\ Faculty of Agricultural Sciences, Food Industry and Environmental Protection, Lucian Blaga University of \\ Sibiu, Romania.e-mail: ovidiutita@yahoo.com
}

ANTOFIE Maria Mihaela, Ph.D Lecturer

Faculty of Agricultural Sciences, Food Industry and Environmental Protection, Lucian Blaga University of Sibiu, Romania. e-mail: mihaela_antofie@yahoo.com

SAVA Camelia, Prof.univ.dr.ing

Faculty of Agricultural Sciences, Food Industry and Environmental Protection, Lucian Blaga University of Sibiu, Romania.e-mail: camelia.sand@yahoo.com

\begin{abstract}
Plantago ovata is economically an important medicinal plant commonly cultivated in different parts of India, Pakistan and Iran and some part of Europe. It has a long history of traditional uses with healing properties. There are various applications of seed husk and its marketable products for medicine and industrial uses. The seed husk is commonly called as psyllium or isabgol has a potential role in the treatment and prevention of gastrointestinal and bowel diseases. The intent of this review was to highlight the industrial uses of psyllium for the food products and therapeutic purposes. There is also considerable interest of local people, scientific communities and industries in the medical and food supplement application of psyllium husk and mucilage with specific health benefits.
\end{abstract}

Key words: Food processing industry, Psyllium, Plantago ovata, Marketable Product, Seed husk

\section{Introduction}

Plantago ovata commonly known as 'psyllium' in English and 'isabgol' in Hindi belongs to the family of Plantaginaceae, is a short stemmed 10-45 cm tall, annual herb. P. ovata is one of major medicinal crops with industrial significance with various applications in food products and drug supporting agent [ 1]. P. ovata have been extensively used commercially for the production of seed husk; a white thin membrane covering of the seed has higher mucilage content derived from husk when soaked in water [ 2]. The scope of this study was to summarize the medicinal and health benefit of psyllium in order to make this plant more prominent in market place where it had negligible attention. Mainly in this study, we tried to address the issues of today life style which increases the risk of developing overweight, constipation due to food deficient of dietary fiber in children and adults. In relation to the issues, the objective of this study was to highlight the uses of psyllium in different aspects not only for pharmaceutical use but also for food processing industries. In order to achieve higher goals of success we need to develop efficient technologies for improvement of varieties through breeding and increase the research work for the identification of other phytochemical with unique medicinal properties.

\section{History}

The word Plantago is originating from Latin, meaning 'sole of the foot', and ovata refers to the shape of the leaves. Psyllium is a Greek origin word, meaning 'Flea' regarding to the colour, shape and size of seeds. Isapghol derived from Persian with meaning of 'horse ear' because of boat shape of seeds. The species of Plantago is indigenous to India, Pakistan and introduced it as medicinal plant by Muslims [ 3]. Therefore, first time it was brought under cultivation in cities of Pakistan i.e., Lahore and Multan. Initially the people of Asian countries used it as a remedy for chronic dysentery and other intestinal problems [ 4]. Some previous studies showed that isabgol has and had long history of uses for medicinal purposes and cultivated long ago by the people for curing of ailments. 


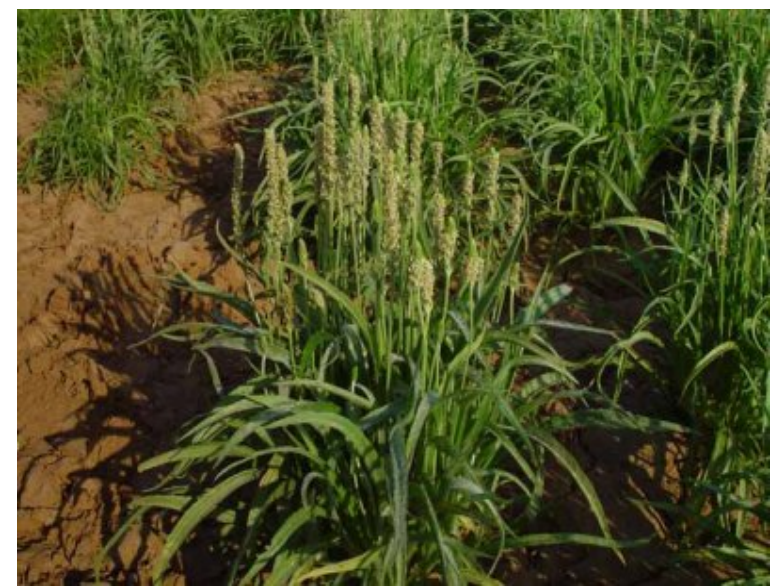

Source: (http://bestpsyllium.com/)

Figure 1: Plantago ovata native to India

\section{Traditional uses}

Traditionally, psyllium husk has been used in Asia and Europe since 16th century as an herbal medicine for chronic constipation [5]. Plantago ovata has a long history of use as fiber supplement because it is rich source of soluble fiber since seeds constitute the commercially important part in the plant. It has also been used in Chinese and Indian traditional system of medicines as safe laxative and reduces the risk of developing chronic diarrhea, dysentery and other intestinal disorders [6]. The seed husk does not irritate the intestine and has specific curing properties when mucous membrane is disturbed by inflammatory infections. Moreover, plant is regarded as a remedy for various ailments in traditional system of medicine in different parts of the world. Seed husk is the main constituent of a number of laxative preparations containing sodium bicarbonate and various flavours used in modern medicine. In India and Pakistan its seeds are considered as cooling and diuretic in functionality and accredited for their usefulness in healing of diarrhea, constipation and for gastric problems when decoction of dried seeds taken orally and externally [ $7,8,9]$.

Furthermore, mucilage of the dried seed is used externally as an emollient in different parts of the world whereas in Iran water extract of dried seeds used externally for inflammation and orally taken seeds used for indigestion associated with bile secretion abnormalities. In Thailand and Spain, seeds of this plant used in different ways for the treatment of ailments like cold, diarrhea and chronic constipation [ 10, 11, 12]. There is growing body of literature supporting the beneficial effects of psyllium (mucilaginous material prepared from the seed husk of genus Plantago) for optimal health and diseases prevention.

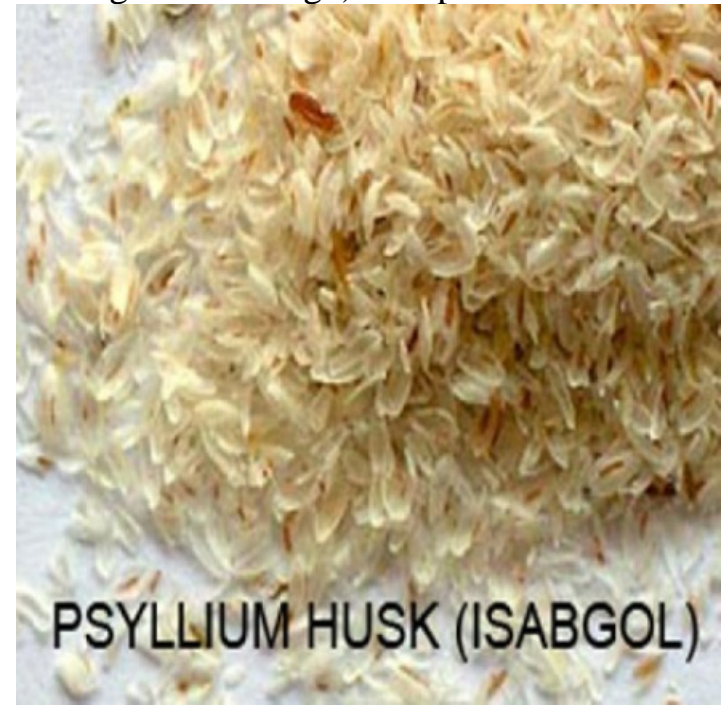

Figure 2: Psyllium husk, mucilage, tasteless material with health benefits

Source: (http://kadampsyllium.blogspot.ro/) 


\section{Pharmacological spectrum application}

During the last decades, much interest has been shown by the scientific community in naturally occurring swell-able biomaterial of Plantago ovata and Ocimum basilicum. These biomaterials are being used as folk medicines. Isabgol has not only traditionally application in life of people but also currently it is utilized in pharmaceutical industry because it was found to be most effective to lower blood cholesterol levels, thereby reducing the risk factors of cardiovascular system diseases which affects more than 80 million people in the world and are the leading cause of mortality in United States [13]. It was found from the previous literature that extract of P. ovata seeds significantly affected the immune system of rabbits. It caused a reduction in anti-HD antibodies as well as an increase in the number of white blood cells and spleen leukocytes. Moreover, aqueous extract of P. ovata seeds reduced hyperglycaemia in type 1 and 2 diabetes in rats. These properties showed that this extract can be used in diabetes treatment [ 14, 15]. Nowadays it gained attention to use as a as a dietary fiber supplement to promote the regulation of bowel function. In pharmaceutical industry, psyllium is used as thickening agent during capsule formulation. Many health benefits are related to dietary fiber obtained from seed husk. For example a sufficient intake of dietary fiber may reduce risk of developing the diseases such as obesity, diabetes and certain gastrointestinal disorders [ 16]. According to results published in the scientific literature mentioned above clearly stated that organic psyllium has much more advantageous for healthy life. Because it was widely considered in medical as safe and effective for certain type of diseases when taken in recommended doses.

\section{Industrial and Market demand}

In developing countries agriculture sector has promising effects on economic growth. To raise the cultivation and quality of economically important crop of small scale farmers may build economic opportunities where they can earn sufficient income from the food markets. Because of medicinal and pharmaceutical application of Plantago ovata, now it has a high value of market demand. In view of increasing market demand, cultivation of this plant at country level or worldwide is utmost important for uplifting the economy of a country. According to scientific report, USA is the chief importer of isabgol seeds and husk and consumes annually 8,000 metric tons which indicate the market value of this crop all over the world. This continued expansion of interest and market seems like due to natural dietary fibers. The crop has a large export demand in USA and Western Europe and about $90 \%$ of the production is exported to these countries. Currently, India is the largest producer and the main supplier of pysllium seed and husk to the world market. [ 17,18$]$.

The seed husk finds variety of applications in food industry because of the remarkable property of mucilage from seed husk as a thickener; it could be used as such in food industries. It is employed as a basic stabilizer in ice-creams and as an ingredient of chocolates and other food products. Psyllium can be used in food and beverages industry as a substitute, thicker and binder such as in health drinks, beverages, ice cream, bread, biscuits, other bakery products, rice, cakes, jams, instant noodles, breakfast cereals etc., in order to improve the fiber content of the food and to increase the bulk of the food with various health benefits. Psyllium Husk may also be added to fresh fruit drinks or flavored drinks to improve the mouthfeel of the drink and make it richer and impart good consistency to it. In food and beverage industry psyllium is use to Improves softness and body texture, to provide strength as binder and stabilizer [ 19, 20].

Furthermore, Plantago ovata contained a product which may some effect on the subjective feeling of fullness and may be a useful supplement in weight control diets which is already taken traditionally by the people world-wide to control bowel function [21].

On the other way, psyllium is used in the pharmaceutical as well as cosmetic industries. The literature confirms that seed husks of P. ovata have found application in the cosmetics industry. It is also used for sizing purpose and as a base in cosmetics. The husk has been found to be served as a good binder and disintegrants in compressed tablets. The isolated mucilage powder of P. ovata exhibits faster drug dissolution and improved bioavailability, and it was stated that the isolated mucilage powder can be effectively used as disintegrants and superdisintegrant in tablet formulations [ 22].

The remains of seed husk around $69 \%$ by weight of the total seed crop can be used as cattle and a bird feed with no adverse or side effects on them [ 23]. Because of international acceptance as medicinal plant lot of efforts exercised to improve the yield and quality of isabgol, there has been only limited success in this concern. Therefore intense efforts are needed for the cultivation of better varieties. This 
may facilitate the production and yield of isabgol with improved quality made it available easily for food products with variety of health comforts.

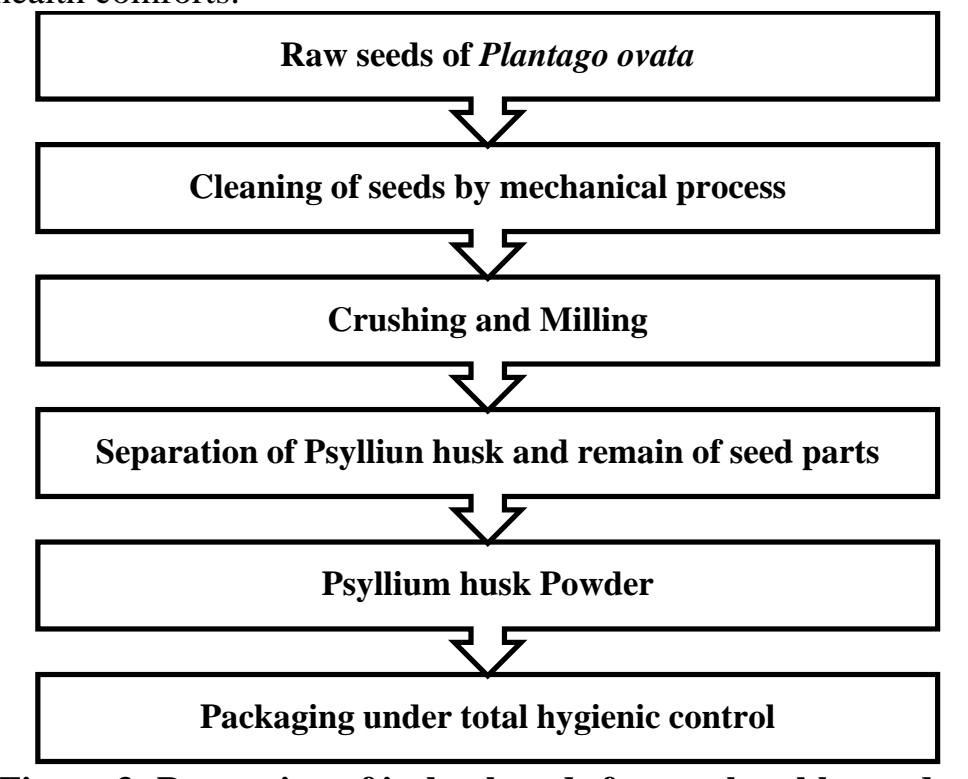

Figure 3: Processing of isabgol seeds for marketable product

\section{Conclusion and Recommendations}

As a result of above discussion regarding commercial and medicinal importance of Plantago ovata, it was concluded that the cultivation and the improvement of culture technologies of this crop at large scale is utmost necessary for need of present time. Thus, it may become a profitable agro-practice for the local people and farmers of that area in the context of developing policy for connecting crop production with the suppliers for industry.

The plant has been cultivated in India and Pakistan from century ago and traditional knowledge access is an asset easy to be explored. Keeping in mind the wide industrial application as well as the increased market demands, appropriate method of cultivation and advance techniques needs to be developed to enhance the yield and the quality of seeds and to get over the traditional process of milling the seeds. On the other hand, seeds may be used for preparation of high valued commercial products. It is desirable to explore the possibilities of intensify cultivation and yield of crop other than arable land which is not suitable for the cultivation of food crops.

Moreover, it was concluded from the previous literature that isabgol seeds has the richest fiber contents consumed as natural source of fiber with various health benefits. This is the main cause of increasing interest of scientific community to do more research work in this direction in order to find newer ways to incorporate this fiber into dietary food products with health protective effects. Psyllium addition in standard diet may support controlling those issues related to food deficient of soluble fiber. From the foregone discussion, we may conclude that Plantago ovata has potential role in industries for marketable product development and for benefit of a healthy society.

However, higher fiber food may play an important role in helping some individuals achieve fiber intakes to control weight enhancement. For all this to happen, health authorities and food producers may be required a strong communication and to educate the public about the health benefits of psyllium.

In order to make this process functional we need to introduce innovative ways to educate the consumers about the strong health effects of organic dietary fibers. Although, enough scientific evidences supported the functional benefits of psyllium with health claims but further studies are needed to explore and elucidate the mechanisms for development of new products that has adequate fibers for prevention of cardiovascular diseases. In this sense, development of staple food products enriched with psyllium husk by food industry will be a potential contribution to a broader supply of food products with soluble fiber. Regarding these initiatives for building of economic opportunities, government and research institutes can play important role in financing of further research in this domain and communicating progress in other public institutes.

\section{Acknowledgment}

This research was realized in a $\mathrm{PhD}$ research program and supported by the Lucian Blaga University of Sibiu, Romania. 


\section{References}

- Jamwal. Studies on some aspects of male sterility in Plantago ovata Forsk. PhD Thesis; University of Jammu,: Jammu, India., 2000.

- Hyde, B. B. Mucilage producing cells in the seed coat of Plantago ovata: development fine structure. American Journal of Botany 1970., 57, 1197-1206.

- Husain, A. Achievements in the research on medicinal plants, their present and future value in India. In: Proceedings of the Fourth Symposium of Pharmacognosy and Chemistry of Natural Products, Leiden, 1977.

- Dhar, M. K.; Kaul, S.; Sareen, S.; Koul, A. K. Plantago ovata: genetic diversity, cultivation, utilization and chemistry. Plant Genetic Resources: characterization and utilization,. 2005, 3(02), 252- 263.

- Abbas, J. A.; El-Oqlah, A. A.; Mahaneh, A. M. Herbal plants in the traditional medicine of Bahrain. Economic Botany 1992, 46, 158-163.

- Montague, J. F. Psyllium seeds: the latest laxative, Montague Hospital for Intestinal Ailments; New York, USA, 1932.

- Dagar, J. C.; Kumar, Y.; Tomar, O. S. Cultivation of medicinal isabgol (Plantago ovata) in alkali soils in semiarid regions of northern India. Land Degradation and Development 2006. 17, 275283.

- Shah, G. L.; Gopal, G. V. Ethnomedical notes from the tribal inhabitants of the north Gujarat (India). J. Econ. Taxon. Botany 1985, (1) (6), 193-201.

- Zahoor, A.; Ghafor, A.; Muhammad, A. Plantago ovata- a crop of arid and dry climates with immense herbal and pharmaceutical importance; Introduction of medicinal herbs and spices as crops Ministry of Food,Agriculture and Livestock: Pakistan, 2004.

- Zagari, A. Medicinal plants, 5th ed.; Tehran University Publications: Tehran, Iran, 1992; Vol. 4, p 969.

- Martinez-Lirola, M. J.; Gonzalez- Tejero, M. R.; Molero-Mesa, J. Ethnobotanical resources in the province of Almeria, Spain:Campos de Nijar. Econ Bot 1996, (1) (50), 40-56.

- Jewvachdamrongkul, Y.; Dechatiwongtse, T.; Pecharaply, D.; Bansiddhi, J.; Kanchanapee, P. Identification of some Thai medicinal plants. Mahidol Univ. J. Pharm. Sci 1982, 3 (9), 65-73.

- Solà, R.; Godàs, G.; Ribalta, J.; Vallvé, J. C.; Girona, J.; Anguera, A.; Ostos, M. A.; Recalde, D.; Salazar, J.; Caslake, M.; Martín-Luj án, F.; Sal s-Salvadó, J.; Masana, L. Effects of soluble fiber (Plantago ovata husk) on plasma lipids, lipoproteins and apolipoproteins in men with ischemic heart disease. Am. J. Clin. Nutr 2007. 85, 1157-1163.

- Rezaeipoor, R.; Saeidnia, S.; Kamalinejad, M. The effect of Plantago ovata on humoral immune responses in experimental animals. J. Ethnopharm 2000, (1-2) (72), 283-286.

- Kordošová, A.; Machová, E. Antioxidant activity of medicinal plants polysaccharides. Fitoterapia 2006. 77, 367-373.

- Montonen, J.; Knekt, P.; Jarvinen, R.; Aromaa, A.; Reunane, A. Whole-grain and fiber intake and the incidence of type 2 diabetes. Am J Clin Nutr.. 2003. 77, 622-629.

- Anon. Market for selected medicinal plants and their derivatives, UNCTAD/GATT; Geneva, Switzerland, 1982.

- Modi, J. M.; Mehta, K. G.; Gupta, R. Isabgol, a dollar earner of North Gujarat. Indian Farming 1974. 23, 17-19.

- Dhar, M. K.; Kaul, S.; Jamwal, S. Plantago ovata Forsk. In: Gupta SK (ed.) Plant Breeding: Theory and Techniques. India Agrobios 2000. 56-67.

- Chan, J. K.; Wypyszyk, V. A forgotten natural dietary fiber: psyllium mucilloid. Cereal Foods World 1988. 33, 919-922.

- Turnbull, W. H.; Thomas, H. G. The effect of a Plantago ovata seed containing preparation on appetite variables, nutrient and energy intake. Int J Obes Relat Metab Disord.. 1995.5 (19), 338342.

- Khinchi, M. P.; Gupta, M. K.; Bhandari, A.; Agarwal, D.; Sharma, N. Studies on the disintegrant properties of seed powder, husk powder and mucilage of Plantago ovata by formulation of orally disintegrating tablet. International Journal of Pharmaceutical Sciences and Research 2011, 1 (2), 145-152.

- Anon. The Wealth of India - Raw Materials. Council of Scientific and Industrial Research 1989, VIII, 146-154. 